\title{
Una luz tras las rejas para los condenados: cambios en la forma de computar la prisión preventiva en la provincia de Buenos Aires en 1915
}

A light behind bars for the doomed. Changes in the way of computing the preventive prison in 1915 in the province of Buenos Aires

Une vie derrière les barreaux pour les condamnés : changements dans les modes de calcul de la détention provisoire dans la province de Buenos Aires en 1915

\section{Gisela Sedeillan}

\section{OpenEdition}

Journals

Edición electrónica

URL: https://journals.openedition.org/rhj/8078

DOI: $10.4000 /$ rhj. 8078

ISSN: 0719-4153

Editor

ACTO Editores Ltda

Referencia electrónica

Gisela Sedeillan, «Una luz tras las rejas para los condenados: cambios en la forma de computar la prisión preventiva en la provincia de Buenos Aires en 1915», Revista Historia y Justicia [En línea], $16 \mid$ 2021, Publicado el 28 julio 2021, consultado el 30 julio 2021. URL: http://journals.openedition.org/rhj/ 8078 ; DOI: https://doi.org/10.4000/rhj.8078

Este documento fue generado automáticamente el 30 julio 2021.

Revista Historia y Justicia 


\title{
Una luz tras las rejas para los condenados: cambios en la forma de computar la prisión preventiva en la provincia de Buenos Aires en 1915
}

\author{
A light behind bars for the doomed. Changes in the way of computing the \\ preventive prison in 1915 in the province of Buenos Aires \\ Une vie derrière les barreaux pour les condamnés : changements dans les modes \\ de calcul de la détention provisoire dans la province de Buenos Aires en 1915
}

Gisela Sedeillan

\section{NOTA DEL EDITOR}

Recibido : 31/12/2020 / Aceptado :14/04/2021

\section{Introducción}

En 1915, desde el penal de Sierra Chica, B. Caunedo -quien se encontraba preso desde hacía más de siete años por una condena a 14 años de presidio por homicidio- solicitaba a la Cámara de Apelación que hiciera un nuevo cómputo del vencimiento de su pena ${ }^{1}$. Al igual que él, otros condenados elevaban el mismo pedido, lo que sugiere que había circulado información acerca de la reforma introducida en la legislación procesal penal con relación al modo de descontar el tiempo de prisión preventiva. En la Argentina, el encarcelamiento preventivo estaba ligado a la duración del proceso: mientras más se prolongaba, más perjudicaba a quien fuera condenado a presidio o penitenciaria porque el primer Código Penal de la Nación, en vigencia desde 1887, fijó en su artículo 49 que tres días de prisión preventiva equivalían a uno de presidio y dos días a uno de 
penitenciaría ${ }^{2}$. Esta diferenciación, justificada en la mayor severidad que se preveía para la ejecución de esa clase de penas, implicó que los 5 meses y 20 días que Caunedo estuvo detenido preventivamente solo le valieran 1 mes y 27 días de pena, en otros casos los perjuicios eran mayores porque los procesos se extendían por más tiempo. A fin de limitar esta injusticia la legislatura de la provincia de Buenos Aires innovó en la materia, por cuanto estableció en el Código Procesal Penal de 1915 que, cumplidos los dos meses de prisión, cada día transcurrido se descontaría por entero de la condena.

2 Como señala La Rosa, "son las reglas sobre encarcelamiento preventivo las que nos permiten conocer cuán autoritario y arbitrario puede ser el poder penal del Estado o cuán respetuoso lo es de los derechos fundamentales del individuo"3. Al codificarse el derecho en la Argentina, el régimen clásico de la prisión preventiva estaba regulado en la ley por la gravedad del delito incriminado, cuando la pena prevista excediera de dos años de prisión ${ }^{4}$ y no existía límite en cuanto a su duración ${ }^{5}$. Al respecto, Salvatore destaca que, a fines del siglo XIX, no solo se castigó bajo dicha forma la mayoría de los delitos, sino que se hizo menos frecuente el otorgamiento de la libertad bajo fianza, lo que implicó muchas situaciones de trato desigual e injusto ${ }^{6}$. Precisamente, la legislación que reguló el funcionamiento del sistema judicial, como indica Caimari, explica en gran parte el histórico carácter mixto -procesados y condenados- de la población penal argentina ${ }^{7}$. De ocho mil presos en 1906, más del sesenta por ciento esperaban el resultado de sus juicios en reclusión, porcentaje que se mantuvo por encima del cincuenta por ciento a lo largo de todo el siglo $\mathrm{XX}^{8}$.

3 La utilización de la prisión preventiva con fines intimidatorios o disuasivos fue muy amplia a lo largo de la historia en diferentes países. Ferrajoli sostiene que su legitimación echó profundas raíces en todos los ordenamientos europeos y terminó siendo justificada en nombre de "necesidades" diversas por todo el pensamiento liberal clásico ${ }^{9}$. A pesar de que esta problemática es muy antigua en Argentina, gran parte de los trabajos sobre el tema, en su mayoría jurisprudenciales y doctrinales, detienen la mirada en particular en las últimas décadas del siglo $\mathrm{XX}$ y principios del $\mathrm{XXI}^{10}$. Teniendo en cuenta que la justicia funciona como un campo no carente de contradicciones ${ }^{11}$, identificar si existieron en diferentes momentos tensiones al aplicar este instituto entre jueces, defensores y fiscales, si hubo intentos por mitigar sus efectos adversos y si estos influyeron o determinaron las reformas legales que acaecieron, es solo una parte de los variados aspectos que merecen profundizarse desde un enfoque de análisis a escala regional.

4 En trabajos previos nos centramos en el funcionamiento de algunos tribunales de la provincia de Buenos Aires a fines del siglo XIX y principios del XX, a fin de dar cuenta de ciertas limitaciones que existían para condenar a los responsables de los delitos, problemática que explica en gran parte las razones de la amplia regulación de la prisión preventiva ${ }^{12}$. También focalizamos la atención en la legislatura bonaerense con el propósito de analizar las propuestas que surgieron con el objetivo de reducir los efectos lesivos de ese instituto y fortalecer el principio de presunción de inocencia en el juicio penal ${ }^{13}$. Dichos proyectos, enmarcados en un contexto de cuestionamientos a la legislación tanto por su rigurosidad como por no atender algunos postulados de la escuela positivista, condujeron a la sanción del Código Procesal Penal de 1915. La provincia con este corpus, "procuró apartarse del procedimiento modelado por el sistema inquisitivo radicalizado, [...]incorporando el juicio oral y público para ciertos casos, pero sin llegar a concretizar un método inspirado en el sistema acusatorio" ${ }^{14}$. 
Dichas investigaciones resultaron en disparadores de nuevos interrogantes, centrados en esta oportunidad en indagar cómo se aplicó en la provincia de Buenos Aires el artículo 49 del Código Penal antes de la sanción del Código Procesal Penal de 1915, por cuanto el cómputo de la prisión preventiva era una de las expresiones más violentas de coerción estatal debido a la dilación de los procesos. La pregunta central que anima el trabajo es conocer si en un contexto en el que emergieron críticas a la legislación por su severidad, los jueces fijaron algún límite al poder punitivo estatal brindando una interpretación más benigna de la ley cuando los procesos se prolongaban en el tiempo. Buscamos responder esta incógnita con el propósito principal de dar cuenta de la relevancia y del impacto real que en aquella época tuvo una reforma legal que hoy, a la distancia, nos puede parecer tenue. Por tal motivo, la interpretación de la nueva ley al momento de entrar en vigor también será objeto de atención ${ }^{15}$.

Nos centraremos en el departamento judicial del Sud, con sede de los tribunales en la ciudad de Dolores, uno de los cinco departamentos judiciales que existían en la provincia de Buenos Aires hasta que se creó en 1915 el de Sudoeste ${ }^{16}$. De un total 2.066.948 habitantes según el censo de 1914, el departamento de Capital y el del Centro eran los que mayor población concentraban, 878.039 y 424.980 respectivamente, mientras que el departamento del Sud contabilizaba un total de 176.133 personas ${ }^{17}$. Efectuamos un análisis cualitativo basado en 40 expedientes judiciales conservados por delitos de homicidio, heridas y atentados a la propiedad cuyas sentencias fueron dictadas entre 1896 y 1915. Los imputados eran de sexo masculino, de diferentes nacionalidades -argentinos, españoles e italianos- $y$, en su mayoría, analfabetos, solteros y jornaleros -trabajadores dedicados a tareas estacionales en el campo. También consultamos los Libros de la Cámara de Apelación, que reunían todos los fallos elevados en apelación o consulta. Asimismo, fueron objeto de análisis los Libros de Acuerdos y Sentencias de la Corte Suprema ${ }^{18}$.

\section{El cómputo de la prisión preventiva y la duración de los procesos: propuestas de reforma}

7 En la Argentina, a principios del siglo XX, el sistema penal fue foco de críticas crecientes en un escenario de influencia de la criminología positivista. La ley 4.189 sancionada por el Congreso Nacional en 1903, fue criticada ni bien entró en vigor porque en respuesta al incremento de la criminalidad acaecido con el impacto demográfico aumentó marcadamente las penas e impidió conmutar las leves de manera pecuniaria ${ }^{19}$. Intelectuales y políticos identificados con el reformismo liberal cuestionaron los principios de la escuela clásica de derecho penal centrados en la concepción "objetiva" del delito y fundamentaron el castigo en razones de "defensa social". Asimismo, señalaron la necesidad de dictar políticas sociales que apuntaran a modificar las causas determinantes de las conductas delictivas. Con respecto a la justicia penal fueron variados los temas de discusión: el aumento de las causas, la cantidad de procesados en espera de una condena, y la necesidad de flexibilizar las penas y restringir la prisión preventiva. Por tal motivo, por encargo del ejecutivo nacional, se redactó un proyecto de reforma del código penal en 1906, aunque lejos estuvo de sancionarse por esos años ${ }^{20}$.

8 En la legislatura bonaerense también comenzó a resonar con fuerza en los discursos de algunos legisladores especialistas en derecho la necesidad de mejorar la prestación del 
servicio de justicia penal ante la sobrepoblación carcelaria. Como hemos señalado en otros trabajos, la reforma de la justicia cobró mayor gravitación con el ingreso de T. Jofré a la Cámara de Diputados en 1907, quien tuvo un papel importante en promover cambios en el proceso penal y construir consensos a fin de reformar la legislación procesal penal ${ }^{21}$. Podemos identificar a este procesalista en esa corriente reformista liberal que señala Zimmermann: conformada por profesionales ligados al mundo académico y de firmes convicciones progresistas, quienes impulsaron reformas a fin de ofrecer una respuesta eficaz a los problemas coyunturales de la Argentina del cambio de siglo ${ }^{22}$. Junto a él, otros abogados arribados a la legislatura participaron en distintas comisiones a fin de modificar el sistema penal, si bien difirieron en más de una ocasión en las medidas a implementar, sus proyectos muestran una preocupación compartida acerca de la necesidad de fortalecer los derechos del imputado en el proceso penal y agilizar la administración de justicia ${ }^{23}$.

Como señala Salvatore, la codificación del derecho penal experimentada en las últimas décadas del siglo XIX en Argentina no trajo aparejada mayores garantías individuales. El proceso se caracterizó por sus rasgos inquisitivos, secreto y escrito, defensas públicas precarias y la retardación de la justicia potenciada por la mayor burocratización y el formalismo de los procedimientos. Uno de los datos relevantes del sistema penal fue su selectividad reflejada en la gran cantidad de procesados, en su mayoría hombres pobres que colmaban las cárceles. ${ }^{24}$ En este sentido, Caimari destaca la regulación de la prisión preventiva sin límite de tiempo y la lentitud de los procesos judiciales atravesados por diferentes instancias. Estos hechos explican que primaran en los establecimientos carcelarios de Argentina los procesados por sobre los condenados ${ }^{25}$. En la provincia de Buenos Aires, el censo carcelario de 1906 contabilizaba un total de 1.797 procesados y 761 condenados -408 a presidio, 209 a penitenciaria y 130 prisión ${ }^{26}$. Dicha población se encontraba distribuida entre el penal de Sierra Chica y las cárceles ubicadas en las sedes de los departamentos judiciales surgidos durante la segunda mitad del siglo XIX a fin de establecer el control estatal en el territorio bonaerense ${ }^{27}$.

Distintos estudios han manifestado que la prisión preventiva fue utilizada como una herramienta de política criminal a lo largo de la historia para disuadir la comisión de delitos, con una finalidad diferente a la cautelar ${ }^{28}$. En muchos casos operaba como una pena anticipada y en otros era la expresión más notoria de injusticia ya que no era menor la proporción de procesados privados de libertad que terminaban absueltos ${ }^{29}$. Hemos señalado, deteniendo la mirada en el departamento judicial del Sud a fines del siglo XIX, que no necesariamente los rasgos inquisitivos del proceso penal conducían a una sentencia condenatoria, pues una gran cantidad de causas tramitadas en los juzgados concluyeron en sobreseimientos o absoluciones por diferentes razones, entre ellas cabe destacar la común precariedad de las pruebas reunidas durante el proceso ${ }^{30}$. Ante esta realidad, el encarcelamiento preventivo constituyó un recurso de control social que permitía evitar la percepción pública de impunidad delictiva; de ahí que construir consensos en la legislatura bonaerense a fin de racionalizar su uso no fuera fácil para quienes animaban una reforma en tal sentido ${ }^{31}$.

La problemática de la prisión preventiva, como ha señalado Pastor, va atada a la de duración del proceso $^{32}$. En el período tratado el tiempo legal previsto para que el proceso culminara en todas sus instancias era de un máximo de dos años. Ese concepto de razonabilidad establecido en la ley procesal provenía de las leyes de partidas y parece haber sido la inspiración que llevó a que se adoptara como plazo en el Código de 
Procedimientos en lo Criminal para la Justicia Federal del año $1888^{33}$. Este corpus fue sancionado con leves modificaciones por la legislatura de la provincia de Buenos Aires en 1896 y experimentó reformas a fin de acelerar la terminación de los juicios en $1906^{34}$. No obstante, la ley no estableció consecuencias que resguardaran al procesado en caso de que se traspasara ese término, por cuanto no determinó el fin del encarcelamiento preventivo. Vale destacar que tampoco fijó un plazo máximo de tiempo para el cómputo diferencial de la prisión preventiva, lo que afectó a condenados a presidio o penitenciaría debido a la prolongación de los procesos.

Múltiples y variadas causas intervenían en la morosidad judicial a fines del siglo XIX y principios del XX en la provincia de Buenos Aires, siendo frecuente que los procesos superaran los dos años de duración. Al excesivo formalismo del procedimiento escrito se sumaba la falta de personal para responder al aumento de la litigiosidad, la lenta cobertura de vacantes y la poca laboriosidad de muchos de los funcionarios judiciales. Esto último generaba una preocupación compartida por algunos legisladores bonaerenses, quienes en esos años pusieron la lupa en el desempeño judicial y les exigieron a los jueces mayor productividad ${ }^{35}$. También los inconvenientes que ocasionaba el procedimiento estatuido en segunda instancia conspiraban en contra de la agilidad procesal: al estar las Cámaras de Apelación obligadas a fallar con la totalidad de sus miembros, era común que la ausencia o impedimento de alguno de los jueces retardara la culminación de los juicios. Este problema no era nada menor si se considera la amplia competencia que tenían esos tribunales como órgano de consulta ${ }^{36}$.

La duración que experimentaban los procesos no parece haberse agravado en el transcurso de la primera década del siglo XX en el departamento analizado. Si bien no podemos hacer generalizaciones sobre el resto de los departamentos judiciales a falta de estadísticas, lo que parece haber adquirido mayor gravitación como problemática a atender en la legislatura bonaerense fue el tiempo de demora del proceso penal desde la perspectiva de los derechos del imputado a ver resuelta su situación procesal en el plazo más breve. Con tal motivo se proyectó aumentar el personal, modificar el procedimiento penal, y establecer plazos más acotados para que los funcionarios se expidan. En 1909 la Cámara de Diputados sancionó un proyecto de código de procedimientos con este objetivo, cuya letra también buscaba restringir la aplicación de la prisión preventiva en delitos correccionales y para los menores de 15 años independientemente del delito incriminado ${ }^{37}$. Sin embargo, dicha propuesta no encontró en el Senado legisladores entusiastas dispuestos a dar preferencia a su discusión. Una de las explicaciones principales de esto parece hundir sus raíces en un contexto de preocupación por el aumento de la criminalidad acaecido con el impacto demográfico y en la dificultad que existía para penalizar los delitos de manera rápida y mediante condena.

Si bien dicho proyecto pasó a archivo al no ser discutido por el Senado, la reducción de los efectos lesivos de la prisión preventiva no dejó de estar en el horizonte de las reformas de algunos legisladores. Con respecto a la forma de descontar los días de encarcelamiento preventivo de la pena, en 1911 el diputado M. De Elizalde propuso que cumplido el año de encierro del encausado se contara un día por un día. ${ }^{38}$. Aunque su proyecto no gozó de tratamiento en particular, existió consenso en incorporar en el proyecto de código de procedimientos que posteriormente se pondría en discusión un límite temporal máximo para computar de manera diferenciada la prisión preventiva, el cual se fijó en dos meses ${ }^{39}$. Una propuesta que resultó innovadora y que dio cuenta 
del exceso en los límites del castigo que representaba por esos años la legislación vigente, no solo porque la duración de los procesos fuera incierta, sino también porque era una realidad el incumplimiento en las cárceles de las distintas formas de represión establecidas en el Código Penal ${ }^{40}$.

Ser condenado a presidio o penitenciaria no implicaba un cambio en el régimen penitenciario al que se estaba sometido durante la prisión preventiva. Como señala Caimari, la gran mayoría de los establecimientos carcelarios se alejaban ampliamente de los proyectos de modernización punitiva que imperaban en los ideales de los reformadores de aquel entonces ${ }^{41}$. Al respecto, la autora sostiene que, con algunas excepciones, las prisiones parecían más bien "pantanos punitivos" que "talleres" diseñados para la rehabilitación de los internos ${ }^{42}$. Precisamente, por la ausencia de distinciones en la ejecución concreta de las penas, en las primeras décadas del siglo XX, la Corte Suprema de la provincia llamó la atención del ejecutivo provincial ${ }^{43}$. El máximo tribunal, que ejercía jurisdicción en las cárceles de detenidos departamentales, le señaló en 1913 que en la cárcel de Mercedes se encontraban 607 presos, aunque solo existía capacidad para alojar a 350, de los cuales 167 eran condenados a distintas penas, por lo que solicitaba su retiro al tratarse de sitios solo previstos para procesados ${ }^{44}$. Ese mismo año, el ministro de gobierno calificó de "deplorable" el estado de estos establecimientos "con una población carcelaria de cerca de cuatro mil procesados, de los cuales apenas quinientos trabajan" 45 .

Desde el ámbito jurídico emanaban distintas voces que clamaban por un sistema que prodigara en menor medida la privación de la libertad ${ }^{46}$. Sin embargo, no parecía existir consenso acerca de que la prisión preventiva pasara a descontarse por entero de toda pena privativa de libertad. El proyecto de reforma del código penal de 1906, redactado por destacados juristas, conservó distinciones en el cómputo de la prisión preventiva en caso de que la condena fuere de reclusión, pena que se introdujo al eliminarse la de presidio y penitenciaria. En ese caso se computaría a razón de dos días de encarcelamiento preventivo por uno de la pena aplicada. Dicha diferenciación seguía justificándose en la naturaleza del castigo, la clase de delitos a los que se aplicaba y el régimen al que necesariamente deberían someterse los condenados. Aquella desigualdad fue calificada de inaceptable y arbitraria por el destacado jurista y legislador Julio Herrera, quien en un libro de su autoría publicado en 1911 sostenía que este instituto iba acompañado de sufrimientos morales intensos a causa de la dolorosa expectativa del procesado ${ }^{47}$. Por todo lo expuesto hasta aquí nos preguntamos si antes de 1915, los jueces se permitieron corregir en algo dicha injusticia cuando los procesos se prolongaban en el tiempo.

\section{Formas de descontar la prisión preventiva en la práctica}

17 El cómputo inequitativo de la prisión preventiva recién terminaba con el último fallo en el que la sentencia quedaba firme. De ser la condena a presidio, penitenciaria o pena capital, el proceso nunca finalizaba en primera instancia porque la legislación procesal penal de 1906 establecía que la Cámara de Apelación debía revisar el fallo aun cuando las partes no hubieran apelado. El abogado defensor tenía la obligación de entablar dicho recurso y, en el caso de que no lo hiciese, al juez le correspondía remitir la sentencia al tribunal. Aunque la consulta era un procedimiento estatuido a favor del 
condenado porque la pena no podía modificarse en un sentido que lo desfavoreciera, el tiempo que tardaba en expedirse el tribunal terminaba por perjudicarlo debido a la forma en que se computaba cada día de prisión. Ello cobraba mayor visibilidad cuando la condena se confirmaba y en los casos en que el proceso se había extendido en el tiempo, como sucedió con J. Fernández y S. Moreno, detenidos el 15 de mayo de 1892 por doble homicidio. La condena del 20 de octubre de 1894 a penitenciaria por tiempo indeterminado recién se confirmó el 17 de septiembre de 1896, después de casi dos años de que la eleven en consulta. Dilación excesiva y no imputable a los procesados que lejos estuvo de ser contemplada al descontarse los 4 años, 4 meses y 12 días de encarcelamiento preventivo, pues solo equivalieron a 2 años, 2 meses y 6 días de condena ${ }^{48}$.

Era una realidad que a fines del siglo XIX e inicios del XX, la elevación del fallo a la Cámara significaba la prolongación del juicio sin tiempos ciertos. Es difícil establecer un promedio de duración de los procesos, porque -como previamente señalamos- cada causa dependía de un cúmulo de circunstancias que variaban en el tiempo entre las que también se encontraban: la cantidad de procesados, las desavenencias entre el juez y la Cámara, el papel desempeñado por el defensor y que el tribunal no estuviera acéfalo. Por entonces, distintos funcionarios se amparaban en los formalismos del procedimiento escrito para no activar los despachos, quienes se veían favorecidos por las deficientes estadísticas sobre el movimiento judicial. Para E. Agüero, por ejemplo, la remisión en apelación de su sentencia a 8 años de presidio por homicidio prolongó por casi un año la culminación del juicio, cuya duración ya de por sí se había extendido en primera instancia del 13 de enero de 1901 hasta el 20 de agosto de 1903. En segunda instancia el defensor se expresó a fines de diciembre de dicho año, el fiscal lo hizo el 20 de febrero de 1904, y la Cámara sentenció un tiempo después, el 15 de julio. Aunque el tribunal redujo la pena a 4 años de presidio, los 3 años, 6 meses y 14 días de prisión preventiva solo le equivalieron 1 año, 2 meses y 5 días de pena ${ }^{49}$.

19 La culminación de las causas se prolongaba por varios meses si se recurría a la Corte Suprema. Además, en esta instancia eran aún más limitadas las posibilidades del condenado de ver mejorada su situación. La falta de destreza y conocimientos del defensor fueron razones de peso que explican que en muchos casos los recursos extraordinarios entablados fueran desestimados, ya sea por no estar debidamente fundados o por no corresponder su interposición, tal como ocurrió con C. Parente, un jornalero, italiano, de 32 años, detenido el 2 de mayo de 1905 por homicidio y condenado en mayo de 1906 a 12 años de presidio, cuya sentencia fue confirmada en agosto de dicho año por la Cámara. La apelación ante la Corte solo sirvió para prolongar el proceso: el 1 de mayo de 1907, el Tribunal dictaminó que era infundado el recurso de inconstitucionalidad e improcedente el de inaplicabilidad porque ya no correspondía en caso de ser las sentencias confirmatorias, a excepción de que impusieran la pena capital o privativa de la libertad por tiempo indeterminado; se trataba de una reforma introducida después de entrar en vigor el Código Procesal de 1906 y sobre la que el defensor parecía no estar informado. Ello implicó que el año, 11 meses y 29 días que experimentó en prisión preventiva solo le equivalieran a ocho meses de presidio ${ }^{50}$.

El cómputo desfavorable de la prisión preventiva afectó a mayor número de condenados después de que comenzara a aplicarse la reforma del Código Penal de la Nación sancionada en 1903. Esto se debe a que aumentaron las penas y pasaron a penalizarse con penitenciaría delitos que antes se castigaban con prisión como por 
ejemplo el hurto de ganado. Los expedientes con condenas a presidio o penitenciaria reflejan que la igualdad ante la ley se hacía ilusoria en la práctica judicial porque el vencimiento de la pena quedaba atado a la desigual duración que caracterizaba cada proceso ${ }^{51}$. Ante esta realidad, a juzgar por los casos analizados, al confirmarse la sentencia el juzgado optó por computar de manera diferenciada el tiempo de prisión preventiva hasta la fecha en que el fallo de primera instancia fuera notificado a las partes. Ello benefició a B. Cuevas, por ejemplo, un jornalero de 26 años condenado a presidio por tiempo indeterminado por un homicidio cometido el 20 de julio de 1903, puesto que la sentencia de primera instancia dictada el 11 de abril de 1904 recién fue confirmada por la Cámara el 10 de marzo de $1905^{52}$. Criterio que también favoreció a $\mathrm{F}$. Moyano, un jornalero de 35 años detenido por lesiones el 1 de noviembre de 1903 y condenado a tres años de penitenciaría el 30 de mayo de 1904, sentencia que recién fue confirmada el 5 de abril de $1905^{53}$. También a D. Astudillo, un jornalero de 19 años encarcelado el 24 de abril de 1903 por homicidio y condenado a 4 años y medio de penitenciaria el 18 de febrero de 1904. Aunque la Cámara confirmó la sentencia el 10 de marzo de 1905, la prisión preventiva solo se computó en la forma establecida en el artículo 49 hasta el 3 de marzo de $1904^{54}$.

21 Aunque no encontramos que el fiscal interviniente haya objetado el criterio implementado por el juzgado, su aplicación no perviviría en el tiempo. El 27 de abril de 1907, la Corte Suprema, a fin de uniformar prácticas, dictó una resolución en la que dispuso expresamente que la prisión preventiva, a los fines de descontarse de la pena en la forma determinada por el artículo 49, terminaba cuando la última sentencia quedara firme. El secretario del presidio de Sierra Chica se encargó de observar el cumplimiento de dicha disposición cuando ingresaban al establecimiento los condenados provenientes de distintas cárceles departamentales de la provincia, quienes lo hacían acompañados del testimonio de la sentencia. Así lo hizo en 1908, por ejemplo, cuando arribó al penal J. Alvarado para seguir cumpliendo la condena a 15 años de presidio por homicidio impuesta por el departamento del Sud, en cuya oportunidad se le solicitó al juez que rectifique la fecha del vencimiento de la pena dado que los días de encarcelamiento preventivo solo se habían contabilizado de manera diferenciada hasta el fallo de primera instancia ${ }^{55}$. De este modo, la intervención de diferentes funcionarios en la ejecución de la pena hizo prevalecer la interpretación de la Corte Suprema, lo cual licuó las acciones tendientes a limitar en algo los perjuicios que ocasionaban que el cómputo de la prisión preventiva estuviera atado a la total duración del proceso y a las contingencias que surgieran en su transcurso.

Aunque la revisión de las resoluciones judiciales no se desenvolvía en límites temporales acotados por cuestiones ajenas a los procesados y el sometimiento a un proceso penal sin límites ciertos comportaba incertidumbre, los defensores comúnmente no reclamaban por la duración de los procesos. En la gran mayoría de los casos la asistencia estaba a cargo de los defensores públicos, quienes tenían poco contacto con sus representados, en algunas ocasiones eran los mismos presos, mediante escritos, quienes realizaban reclamos sobre el proceso o el servicio de defensa ${ }^{56}$. Contribuía a ello el escaso número de defensores y los bajos salarios, compensados por la potestad que les fue concedida de poder abogar de manera privada en materia civil. Fortalecer este servicio fue objeto de especial preocupación para Jofré, quien al ser consciente de que la reforma procesal debía de acompañarse de la ampliación del presupuesto y la prohibición del ejercicio de la profesión, impulsó distintas medidas que no llegaron a concretars ${ }^{57}$. Los llamados de atención de la Corte Suprema dan 
cuenta de la prestación precaria del servicio de defensa pública, una problemática que no era exclusiva de los tribunales judiciales bonaerenses, sino más bien una característica del sistema penal argentino ${ }^{58}$.

Una de las esperanzas que abrigaban los condenados después de ejecutoriada la sentencia era que una vez que hubieran cumplido las dos terceras partes de la condena la Corte Suprema les redujera la pena. Esta potestad le fue concedida al máximo tribunal por la Constitución provincial, siempre que los condenados hubieran gozado de buena conducta ${ }^{59}$. Por ejemplo, la Corte adelantó a R. Martínez en 1907, la fecha de vencimiento de la pena de cuatro años y medio de presidio. Este argentino, jornalero, de 23 años y soltero, fue preso en enero de 1902, sentenciado el 27 de octubre de ese año en primera instancia y el 23 de octubre de 1903 en segunda. El año, 9 meses y 19 días de prisión preventiva solo le habían equivalido a 7 meses y 6 días de la pena de presidio ${ }^{60}$. En este, como en otros casos, el tiempo total experimentado en prisión se incluyó entre los fundamentos que fueron esgrimidos para reducir la condena en algunos meses. Sin embargo, esta medida, que dependía del informe que elevara sobre el penado el establecimiento carcelario, no alcanzaba a compensar la injusticia e incertidumbre que generaba el artículo 49 del Código Penal.

La Corte Suprema era consciente de la incierta duración de los procesos, cuyos tiempos variaban de un juzgado a otro. Por tal motivo, nos preguntamos la postura que asumió el tribunal ante el recurso extraordinario interpuesto por un defensor con el fin de limitar los perjuicios que ocasionaba el cómputo diferencial de la prisión preventiva en casos de excesiva duración del proceso. En 1912, la defensa entabló el recurso de inaplicabilidad de la ley contra un fallo de la Cámara de Apelaciones del departamento judicial del Centro, bajo el argumento de que el plazo máximo para computar la detención cautelar según la forma dispuesta en el artículo 49 era de dos años (término que establecía el Código Procesal para que toda causa finalice) ${ }^{61}$. Del fallo de la Corte se desprende que el defensor sostuvo que de superarse ese límite debía descontarse la prisión preventiva a razón de un día por un día de pena. Si bien la demanda no planteaba la libertad provisional del acusado superado ese límite temporal, no deja de resultar importante, ya que ponía en valor la necesidad de establecer normas regulatorias del tiempo de la prisión preventiva en relación con su cómputo diferenciado. Su sola presentación invitaba a reflexionar acerca de hasta cuándo debía pagar el condenado los costos de la prolongación del proceso sin culpa suya. ¿Podían las reglas establecidas en el artículo 49 continuar siendo defendibles frente a un enjuiciamiento que se había perpetuado en el tiempo?

La Suprema Corte debió expedirse en un contexto donde se ponía bajo la lupa la actuación de los jueces, y en el ámbito político cobraba mayor dimensión los derechos de los imputados para que su situación procesal fuera resuelta en un tiempo menor. Resulta claro que el máximo tribunal no desconocía los datos de la realidad. Justamente en 1912, ante los problemas que presentaban algunos tribunales de la provincia relacionados con la falta de celeridad por ausencia o impedimento de algún vocal, había propuesto a la legislatura medidas que innovaban en el procedimiento penal en segunda instancia. ${ }^{62} \mathrm{~A}$ pesar de existir intersticios para la interpretación de la ley, el procurador Jorge Maurice pidió a los miembros del tribunal desestimar el recurso interpuesto. Coincidió con la Cámara en que la prisión preventiva debía computarse conforme a lo dispuesto en el artículo 49 del Código Penal, la que continuaba hasta que 
quedase firme el último fallo. Ese plazo de dos años fijado en el Código Procesal para Maurice:

[...] constituye una obligación impuesta a la Administración de Justicia para evitar morosidades injustificadas, y se propone, por ende, un beneficio en favor de los encausados, pero no significa, en manera alguna, la modificación de los términos expresos en que está concebido el artículo 49 del Código Penal ${ }^{63}$.

Los miembros del tribunal, M. Escobar, G. Lecot, J. N. Matienzo, E. Rivarola, y M. García Reynoso, coincidieron con el procurador. Lejos estuvieron de efectivizar el plazo de dos años en favor del condenado, ya que interpretaron que la prescripción contenida en el artículo del Código Penal no podía ser modificada por las disposiciones del Código Procesal Penal ${ }^{64}$. Aunque la Corte tuvo la posibilidad de reparar en algo dicha injusticia y sentar jurisprudencia a través de una interpretación analógica de la ley, no lo hizo. Los argumentos vertidos guardaron silencio sobre la extensión del proceso y de esta manera continuó sin darse una solución jurídica al problema. No obstante, en qué medida los departamentos judiciales de la provincia acataron dicha decisión es un aspecto que requiere ser analizado debido a la amplia jurisdicción que tenían las Cámaras de Apelación. Así, lo sugiere una sentencia del tribunal del departamento de Costa Sud que debió revisar la Corte dos años después.

A fines de 1914, la Corte Suprema nuevamente debió resolver al respecto porque un fiscal interpuso el recurso de inaplicabilidad de la ley contra un fallo de la Cámara de Apelación del departamento Costa Sud. El caso afectaba a J. García, quien había sido detenido el 2 de marzo de 1911 y condenado por el delito de robo, disparo de arma de fuego y atentado a la autoridad a seis años de penitenciaría. ${ }^{65}$ Los 3 años, 2 meses y 9 días de prisión preventiva que sufrió hasta que la sentencia quedó consentida por la Cámara equivalieron a 1 año, 7 meses y 5 días de la pena según el cálculo hecho por el juez de primera instancia. Del fallo de la Corte se desprende que el defensor apeló dicho cómputo ante la Cámara de Apelación apoyándose en la jurisprudencia del tribunal, que descontaba a razón de un día de prisión preventiva por un día de pena desde que se cumplieran los dos años de iniciada la causa. Estos argumentos fueron atendidos por la Cámara que interpretó que los dos años fijados por el Código Procesal para que toda causa quede concluida era el límite de tiempo máximo para descontar la prisión preventiva en la forma exigida por el Código Penal. De este modo, la Cámara estableció una rigurosa limitación temporal para realizar el descuento diferencial, aunque resultó menos beneficiosa para el condenado que la fijada en el proyecto del código procesal penal que estaba pronto a sancionarse por la legislatura provincial.

Los miembros de la Corte Suprema nuevamente tenían en sus manos la oportunidad de brindar una respuesta que mitigara los efectos negativos que acarreaba la forma de descontarse el encarcelamiento preventivo. Sin embargo, el procurador E. Johanneton en octubre de 1914, solicitó a la Corte hacer lugar al recurso interpuesto por el fiscal por considerar que la Cámara había aplicado erróneamente la ley. El máximo tribunal se expidió en el mismo sentido el 5 de diciembre de 1914, prácticamente a puertas de la sanción del Código Procesal Penal, aunque esta vez no lo hizo por unanimidad. A favor del recurso se expresó Lecot, quien argumentó que si bien "[...] el artículo 5 citado establece, en verdad, que toda causa deberá terminarse en el término de dos años [...], ese precepto legal no establece una sanción para el caso en que el proceso dure más" 66 . Rivarola opinó en el mismo sentido: "contiene el artículo 5 una disposición que obliga a los jueces y cuya inobservancia les haría incurrir en falta, pero es ajena a la regla contenida en el artículo 49 del Código Penal" ${ }^{67}$. Así también se pronunció Escobar, quien 
sostuvo "Es un principio en materia penal que la ley no puede aplicarse por analogía. Tratándose de establecer el cómputo de la prisión preventiva, debe aplicarse el artículo 49 del Código Penal que legisla exclusivamente sobre este punto"68.

Debe rescatarse el voto en disidencia de Llambí, magistrado recién arribado al tribunal que se apartó del resto de los miembros y sentó argumentos que son de forzosa observación, por cuanto brindó una respuesta jurídica al núcleo del problema, aunque lejos estaba de ser compensatoria de tal injusticia. Este vocal, a diferencia de Escobar, interpretó que establecer un plazo máximo a partir del cual comenzar a descontar la prisión preventiva de manera equitativa no implicaba contradecir al Código Penal:

El artículo 49 del Código Penal, si bien ha determinado la forma como debe computarse la prisión preventiva, no ha fijado el tiempo que ella debe durar [...] Ahora bien, si el proceso debe terminar en dos años, sin esfuerzo se deduce que en ese plazo debe terminar la prisión preventiva, que es, por regla general, un trámite del juicio. Interpretar de otra manera esa disposición legal, importaría dejar librado a la voluntad de los jueces el tiempo de prevención de la libertad de las personas, demorando el proceso. Se dirá que esto es una falta en el magistrado, pero con tal declaración no se retrotrae el tiempo perdido para el encausado. A mi modo de pensar, los artículos de que me ocupo están íntimamente relacionados, pues la ley de fondo fija la forma cómo se computa la prisión preventiva y la de procedimientos el tiempo que ella debe durar ${ }^{69}$.

Como puede apreciarse, la vulneración de los derechos que ocasionaba un proceso penal que se prolongaba indefinidamente en el tiempo formó parte de los fundamentos en los que giró su argumentación. Se observa con claridad que el encarcelamiento preventivo desde la perspectiva de su duración y la necesidad de establecer un plazo más allá del cual era inadmisible, en este caso tampoco se planteó con el fin de otorgar la libertad del acusado. Aun así, la mayoría de los miembros de la Corte fueron restrictivos en su alcance jurisprudencial y negaron la posibilidad de otorgar algo de equidad al derecho ${ }^{70}$.

31 Más allá de esta interpretación cabe preguntarse si los jueces introdujeron alguna compensación al procesado por la morosidad judicial. El Código Penal en su artículo 83, inciso 8, establecía que en los delitos que merezcan pena capital, cuando la causa durase más de dos años, sin culpa del procesado o de su defensor, debía considerarse como circunstancia atenuante. En el departamento judicial analizado, solo en algunos casos de condenas a presidio o penitenciaria se redujo la penalidad por dicha causa, por lo que lejos estuvo de compensar la injusticia que comportaba el artículo 49. Era un beneficio que quedaba librado a la discrecionalidad del juez y del que no podían gozar todos los condenados que hubieran transitado un proceso cuya duración fuese menor a ese límite arbitrario establecido.

Recién la atemperación del rigor en la forma de computarse la prisión preventiva llegó en 1915 con la sanción del Código Procesal Penal, el cual estableció un límite de tiempo para descontar cada día de manera diferenciada. Aunque este criterio, como vimos, ya lo habían ensayado algunos jueces, el término establecido en la ley fue mucho más acotado. El artículo 449 dispuso de manera expresa y categórica que: "La prisión preventiva a los efectos del artículo 49 del código penal, terminará a los dos meses de detenida una persona, si a ésta se le impusiere pena de penitenciaria o presidio. La sentencia condenatoria tendrá efecto retroactivo a esa fecha"71. El Código también introdujo otras reformas con respecto a este instituto: prohibió su aplicación en caso de 
menores de 15 años independientemente de la gravedad del delito incriminado y la restringió en delitos correccionales ${ }^{72}$.

\section{Los funcionarios judiciales ante la nueva ley}

La reforma llegó a ver la luz cuando la duración de los procesos judiciales se había reducido en comparación con la década de 1890 y principios del siglo XX, al menos en el departamento Sud los procesos habían ganado en celeridad. En la generalidad de los casos, las causas graves no superaban el año y medio de duración, por el contrario, se resolvían en un tiempo mucho menor. Contribuyó a ello el hecho de que al departamento analizado se le restaran partidos que tenía bajo su jurisdicción al crearse el departamento de Costa Sud y también la instalación de un segundo juzgado en lo penal, entre otras razones. No obstante, esta realidad está lejos de opacar los beneficios introducidos por el Código Procesal Penal, por cuanto el artículo 449 otorgó al procesado la certeza de cómo se descontarían los días de encarcelamiento preventivo, lo que ya no quedaba atado al tiempo del proceso. Vale destacar que su letra no solo redujo en este aspecto la incertidumbre y lesividad que generaba la duración del proceso penal, sino que también suscitó expectativas en quienes ya habían sido condenados al permitir interponer el recurso de revisión de la fecha de vencimiento de la condena.

La legislación procesal anterior a 1915 posibilitaba a los condenados la revisión del procedimiento cerrado por sentencia pasada en autoridad de cosa juzgada, por ejemplo, cuando por ley posterior se haya declarado que no es punible el acto que antes se consideraba como tal, o cuando haya disminuido su penalidad. Se trataba de un recurso extraordinario a su favor, cuya finalidad era no someter a una persona inocente a una pena que no mereciese o a un condenado a una mayor de la que le correspondiese ${ }^{73}$. El inciso 5 del artículo 311 del Código procesal de 1915 hizo taxativo, a fin de no generar dudas, que este recurso también podía interponerse cuando por ley se hubiera modificado "la manera de computar la prisión preventiva en forma favorable al acusado"74. No se establecieron plazos al respecto, solo debía hacerse la presentación ante la Cámara de Apelación, en cuyo tribunal descansaba su admisibilidad. Únicamente se exigía como requisito que el escrito se acompañara del testimonio de la sentencia y los documentos y pruebas correspondientes; caso contrario sería desechado de plano (Art. 316) ${ }^{75}$. Resulta pertinente preguntarse si estaban los condenados en condiciones de cumplir con dichos formalismos.

Después de varios meses de que la ley entrara en vigor, llegaron a la Cámara de Apelación algunas solicitudes firmadas por los condenados a fin de que se efectuara un nuevo cálculo del tiempo de pena que debían cumplir. El patrón repetido de los escritos sugiere que de alguna manera circuló un modelo entre los mismos presos, quienes no contaban con abogado particular, como en su mayoría tampoco lo habían tenido cuando fueron procesados. En la solicitud no se empleaban retóricas discursivas a fin de convencer a los magistrados, (por ejemplo, no se apelaba a la injusticia de la extensa duración del proceso que habían experimentado), sino que solo se limitaban a citar los dos nuevos artículos del Código Procesal sancionado (Art. 449 y 311). Ello permite hipotetizar sobre el conocimiento cierto que habrían adquirido acerca de los beneficios que encerraba la reforma procesal en forma de derechos, cuyo goce no dependía de la discrecionalidad o buena voluntad del juez. En el espacio de la cárcel, como han 
señalado distintos estudios, podían existir variados canales por los que circulaba información que posibilitaba a los detenidos, incluso analfabetos, conocer acerca de algunas reformas implementadas, tomar conciencia sobre ellas y hasta desarrollar estrategias de resistencia ${ }^{76}$.

Con fecha del 15 de diciembre de 1915, llegaba una carta de B. Cuevas a la Cámara de Apelación desde el presidio de Sierra Chica solicitándole que revea la fecha de vencimiento de su condena. ${ }^{77} \mathrm{El}$ tribunal dio vista al fiscal, quien, sin embargo, se pronunció a favor de desechar de plano tal solicitud con el argumento de que no se cumplió con el requisito establecido en el Código Procesal para efectuar dicha interposición, ya que el interesado no había acompañado el escrito con el testimonio de sentencia de primera instancia. Con su accionar, interponía una traba innecesaria y carente de razonabilidad respecto de los fines que había perseguido el legislador al sancionar la ley. La Cámara dio vista al defensor público, funcionario que buscó subsanar tal omisión solicitándole que requiriera al juzgado respectivo dicha documentación. ¿Debía el tribunal hacer prevalecer el cumplimiento de los formalismos exigidos en la ley procesal por sobre el derecho del condenado?

A juzgar por los casos analizados, la Cámara de Apelación hizo lugar al pedido del defensor, por lo que la falta de observancia de las formas que debían revestir dichas peticiones no constituyó impedimento para que el cómputo de la condena sea revisado. En 1916 dio curso a esas solicitudes que encerraban como objetivo la aplicación retroactiva de la ley por ser más benigna. No puede resultarnos difícil imaginar cómo el tiempo del proceso penal volvería a cobrar importancia para los condenados, ya que mientras más prolongado hubiera sido, más impacto favorable tendría en la fecha de vencimiento de la condena. En cierto modo, por ejemplo, en el caso de P. López, ello significó un acto mínimo de reparación ante la prolongación que había experimentado su proceso. Este argentino, de veintisiete años, fue detenido el 27 de septiembre de 1890 y se lo condenó por homicidio a presidio por tiempo indeterminado en abril de 1893 , sentencia que recién quedó firme en diciembre de 1896, por lo que los seis años, dos meses y veintinueve días de encarcelamiento preventivo solo le habían valido dos años y un mes de presidio. Con el nuevo cálculo la pena empezó a contarse desde fines de 1890, mientras que antes lo había sido desde noviembre de 1894, es decir que después de 25 años de estar preso esta reforma lo acercaba a su libertad ${ }^{78}$.

En el departamento judicial analizado la aplicación que hizo la Cámara del artículo 449 no fue objetada. Sin embargo, no parece haber sucedido lo mismo en el departamento de Costa Sud, porque el fiscal de Cámara, A. Palomeque, interpuso ante la Corte Suprema los recursos extraordinarios de inconstitucionalidad e inaplicabilidad de dicho artículo por contradecir el artículo 49 del Código Penal. Dado que estos recursos eran admitidos en sentencias que decidían sobre la forma de contabilizar la duración del encarcelamiento preventivo ${ }^{79}$, el máximo tribunal debió resolver al respecto en la causa caratulada A. Méndez por lesiones a E. Mena ${ }^{80}$. Sobre el punto en cuestión ya se había expresado el vocal Llambí en otro fallo, quien como señalamos, había sostenido que la duración de la prisión preventiva era una cuestión meramente procesal. En esta oportunidad el procurador Johanneton se pronunció el 19 de mayo de 1916, desechando el recurso de inaplicabilidad de la ley y admitiendo el de inconstitucionalidad. Sin embargo, la Suprema Corte, conformada por Llambí, Lecot, Rivarola, Escobar y Gnecco, resolvió por unanimidad el 22 de noviembre de 1916 no admitir tampoco el mismo. Argumentó: 
$3^{\circ}$ Que, si bien de los preceptos de los artículos 13, 18 y 19 de la Constitución de la Provincia se desprende la facultad de los Jueces de privar de su libertad a la persona contra quien recaigan indicios vehementes de ser autora de un hecho que merezca pena corporal, la duración de esa detención y su mérito para ser tenida en cuenta a los efectos del cumplimiento de la condena, están regidos por la legislación de fondo o de forma [...].

$4^{\circ}$ Que, si existe conflicto entre esas dos leyes de fondo o de forma, el punto no puede ser resuelto mediante el recurso traído, porque ningún precepto de la Constitución rige el caso ${ }^{81}$. artículo 449. Para el fiscal Palomeque significó un cambio en la jurisprudencia del máximo tribunal: así lo señaló en el año 1916, al publicar un libro crítico sobre el nuevo Código Procesal Penal. De hecho, efectivamente se trató de un cambio; recordemos que el mismo Escobar en 1914 había sostenido que el artículo 49 del Código Penal legislaba exclusivamente sobre este punto. Esta decisión, sin embargo, no la cuestionó el fiscal, sino que, por el contrario, sostuvo: "La respetamos y no la atacamos, porque en el fondo, aunque ella viole indiscutiblemente el Código Penal, es humano que así lo haga"82. Más que centrarse en defender el artículo 49, al que calificó de inhumano y cruel, reprochó a la legislatura provincial por haber legislado en la materia. No dudó en calificar el artículo 449 como un subterfugio legal para no hacer efectiva una ley sancionada por el Congreso Nacional, y señaló que en todo caso lo correcto hubiera sido que éste derogase tal artículo. Para Palomeque "el nuevo código ha venido a concluir con una injusticia, aunque cometiendo una invasión de facultades legislativas" ${ }^{83}$. A esas críticas centradas en la contradicción existente entre los dos cuerpos legislativos respondió el mismo artífice del Código Procesal, Jofré. Vale reproducir sus palabras por cuanto la argumentación que sustentó en defensa de la reforma no se limitó únicamente a consideraciones legales:

El código penal establece la represión; el de procedimiento, sienta las reglas para la marcha del juicio. Y si todavía fuese de dudosa cuestión debería resolverse en el sentido del artículo que nos ocupa. En la provincia, los procesados se encuentran sometidos a un régimen que en nada se diferencia del que soportan los condenados a penitenciaría o presidio. Por otra parte, es absurdo hacer que los reos soporten las consecuencias de la morosidad judicial en la que no tienen ninguna culpa ${ }^{84}$.

Dichas palabras nos recuerdan la intención que animó la sanción de la ley, cuya letra, como hemos destacado, también despertó esperanzas en quienes ya purgaban una condena. Estas razones por sí solas ameritan el esfuerzo de acercar la mirada a otros tribunales judiciales con el fin de conocer en qué medida pudieron hacerse realidad en aquel entonces.

\section{Reflexiones finales}

41 Hoy, al igual que en el pasado, la prisión preventiva sigue siendo una de las problemáticas más controvertidas del derecho penal, de ahí la importancia de explorar la aplicación de este instituto en la práctica desde una perspectiva histórica. Aquí solo nos hemos detenido en un aspecto en particular: los perjuicios e incertidumbre que ocasionó al condenado a presidio y penitenciaria el cómputo diferenciado del tiempo de encarcelamiento preventivo, sin término de duración, establecido en el primer Código Penal Nacional. Los fallos analizados dejan al descubierto algunos intentos de defensores y jueces por imponer límites a la rigurosidad de la ley cuando los procesos 
se prolongaban en el tiempo, entre los que se encontraban fijar un plazo máximo de dos años para descontar la prisión preventiva de manera diferenciada, o hacerlo hasta que fuera dictada la sentencia de primera instancia. Aunque estas respuestas estaban lejos de representar una compensación a la injusticia que comportaba el artículo 49 del Código Penal, la mayoría de los miembros de la Corte Suprema mantuvieron una postura intransigente, pues no ofrecieron una solución jurídica al problema mediante un cambio jurisprudencial. Precisamente, centrarnos en la posición sentada por el máximo tribunal permite reflexionar sobre la significancia que tuvo la reforma procesal penal introducida en 1915.

Es cierto que el Código sancionado no marca el inicio del nuevo modelo procesal penal de orientación acusatoria, que el encarcelamiento preventivo continuó regulado por la gravedad del delito incriminado y no se introdujo un plazo máximo en su duración. Aun así, otorgar límites precisos y acotados a la prisión preventiva con relación a su cómputo diferenciado posibilitó mitigar en algo la injusticia que representaba el artículo 49 del Código Penal, un beneficio al que los condenados en otras provincias estaban lejos de poder acceder. Se trató de una reforma que también generó expectativas a juzgar por las solicitudes que llegaron a la Cámara de Apelación a meses de entrar el nuevo corpus en vigencia y por la forma en que la justicia resolvió al respecto dándoles curso. En consecuencia, representó un acto mínimo de reparación y un freno al ejercicio del poder estatal, aun sin desconocer muchas de las deudas pendientes que quedaban en el camino con respecto a la regulación de este instituto.

Teniendo en cuenta que las prácticas y los discursos jurídicos son producto y también se explican a partir del funcionamiento del campo jurídico y por las relaciones de fuerza que existen en su interior ${ }^{85}$, este trabajo lejos de resultar un punto de arribo conclusivo en torno a la cuestión supone una primera aproximación al tema. Lo que busca es ser un disparador para hurgar en un futuro en otros departamentos judiciales a fin de identificar hasta dónde se permitieron los jueces dar amplitud a la interpretación de la ley cuando la legislatura demoraba dar una solución al problema, o si utilizaron otros modos para racionalizar la aplicación de dicho instituto, ya sea en casos de menores o mujeres, por ejemplo. Por lo pronto, al intentar identificar algunas rigideces que conllevó otorgar mayor protección a las personas perseguidas penalmente, se aspira a contribuir a la reflexión sobre el largo camino que ha implicado el fortalecimiento de sus derechos y con ello pretende aportar al debate actual sobre la necesaria reducción del poder punitivo a manifestaciones más racionales, dado que nuestro pasado da cuenta, y mucho, acerca de su innecesaria lesividad.

\section{Fuentes}

\section{Fuentes inéditas}

Suprema Corte de Buenos Aires, Sección Histórica. Departamento Judicial Dolores. Fondo Penal

Paquete 125, Orden 7;

Paquete 142, Orden 7;

Paquete 235, Orden 21;

Paquete 243. Orden 16;

Paquete 259. Orden 11; 
Paquete 261, Orden 1;

Paquete 261, Orden 12;

Paquete 267. Orden 27;

Paquete 278, Orden 1;

Paquete 300, Orden 2.

\section{Fuentes publicadas}

\section{BIBLIOGRAFÍA}

Aguirre, Carlos, "La cárcel y la ciudad letrada: hacia una historia cultural de la prisión en el Perú del siglo XX”, en: Palma Alvarado, Daniel (Ed.), Delincuentes, policías y justicias en América Latina, siglos XIX-XX, Universidad Alberto Hurtado, Santiago de Chile, 2015, p. 144-192.

Aguirre, Carlos \& Salvatore, Ricardo, "Escribir la historia del derecho, el delito y el castigo en América Latina”, Revista Historia y Justicia, Chile, nº, 2017, p. 224-252.

Alvarado Vellosso, Adolfo, Lecciones de derecho procesal penal. Adaptadas a la legislación procesal y civil penal de la provincia de Buenos Aires, Astrea, Buenos Aires, 2015, 984, p.

Barreneche, Osvaldo, Dentro de la ley TODO. La justicia criminal de Buenos Aires en la etapa formativa del sistema penal moderno de la Argentina, Al Margen, La Plata, 2001, 186, p. 
Barreneche, Osvaldo, "Las instituciones de seguridad y del castigo en Argentina y América Latina. Recorrido historiográfico, desafíos y propuestas de diálogo con la historia del derecho" Revista de Historia de las Prisiones, Argentina, ํำ1, 2015, p. 5-33.

Binder, Alberto, Introducción al derecho procesal penal, Ad-hoc, Buenos Aires, 1999, 261 p.

Brangier, Víctor, “Sentidos de 'lo justo e injusto'. Judicialización de conflictos interpersonales. Chile Central, 1824-1875”, Revista Historia y Justicia, Chile, n¹, 2013, p. 1-33.

Bovino, Alberto, Problemas de derecho procesal penal contemporáneo, Editores del Puerto, Buenos Aires, 1998, $323 \mathrm{p}$.

Bourdieu, Pierre, La fuerza del Derecho: elementos para una sociología del campo jurídico, Uniandes, Bogotá, 2000, 220 p.

Caimari, Lila, Apenas un delincuente. Crimen, castigo y cultura en la Argentina, 1880-1955. Siglo XXI, Buenos Aires, 2004, 308 p.

Caimari, Lila, "Entre la celda y el hogar. Dilemas estatales del castigo femenino, 1890-1940, Nueva Doctrina Penal, n², Buenos Aires, Editores Del Puerto, 2007, p. 427-450.

Caferata Nores, José, Proceso Penal y Derechos humanos, Del Puerto, Buenos. Aires, 2011, 2 ed. 260 p.

Calandria, Sol, "En busca de un nuevo orden provincial. El poder judicial y el fuero penal en la provincia de Buenos Aires (1881-1915)", Revista de Historia del Derecho, Buenos Aires, n51, 2016, p. 17-48.

Calandria, Sol, "Resquicios jurídicos en el discurso del poder: honra y moralidad sexual en los fallos de infanticidio (provincia de Buenos Aires)", Revista Historia y Justicia, Chile, n¹1, 2018, p. 14-41.

Casullo, Fernando, "El estado mira al sur. Administración de justicia en los Territorios Nacionales de Rio Negro y Neuquén. (1884-1920)”, en Bohoslavsky, Ernesto \& Soprano, Germán (comp.) Un Estado con rostro humano. Funcionarios e instituciones estatales en Argentina (de 1880 a la actualidad), Universidad de General Sarmiento/Prometeo, Buenos Aires, 2010, p. 333- 354.

Cesano, José, “Tendencias de la política criminal argentina en el marco de la política criminal latinoamericana. Críticas y sugerencias a partir de un análisis comparativo", Boletín Mexicano de Derecho Comparado, México, n²126, 2009. p. 1281-1303.

Cesano, José, Élites, redes intelectuales y recepción en la cultura jurídico penal de Córdoba: 1900-1950, Del Copista, Córdoba, 2011, 136 p.

Corva, María, Constituir el gobierno, afianzar la justicia. El poder judicial de la provincia de Buenos Aires (1853-1881), Prohistoria, Rosario, 2014, 364 p.

Creazzo, Giuditta, El positivismo criminológico italiano en la Argentina, Ediar, Buenos Aires, 2007, 258 p.

Di Gresia, Leandro, "Una aproximación al estudio de la cultura judicial de la población rural bonaerense: Tres Arroyos, segunda mitad del siglo XIX”, en Barriera, Darío (Coord.), La justicia y las formas de la autoridad. Organización política y justicias locales en territorios de frontera. El Río de la Plata, Córdoba, Cuyo y Tucumán, siglos XVIII-XIX, ISHIR CONICET, Rosario, 2010, p. 155-191.

Dovio, Mariana \& Cesano, José, La criminalidad femenina en el discurso del positivismo criminológico argentino, Brujas, Córdoba, 2009, 117. p.

Edwars, Enrique, Plazos de la prisión preventiva. Ley 24.390, Astrea, Buenos. Aires, 1995,168 p.

Ferrajoli, Luigi, Derecho y Razón, Teoría del garantismo penal, Trotta, Madrid, 2004, 1019 p. 
Freidenraij, Claudia, "Penetrar en el alma del niño": reflexiones sobre el discernimiento de los menores delincuentes (Buenos Aires, 1887-1919), Revista Gioja, Buenos Aires, n¹7, 2016, p. 35-56.

Frías, José, Código penal y código de procedimientos en lo criminal ante la justicia federal. Ordinaria y territorios nacionales, Coni. Hnos., Buenos Aires, 1904, 351 p.

Goodman, Philip \& Page, Joshup \& Phelps, Michelle, Breaking the pendulum. The long struggle over criminal justice, Oxford University Press, Oxford, 2017, 240 p.

Jofré, Tomás, Proyecto de código de procedimiento penal, Talleres Gráficos Suarez, Buenos Aires, $1914,112 \mathrm{p}$.

Jofré, Tomás, El nuevo código de procedimiento penal de la provincia de Buenos Aires, comentado (T. II), Lajouane, Buenos Aires, 1915, 348 p.

Jofré, Tomás, El código penal de 1922, Valerio Aveledo, Buenos Aires, 1922, 402 p.

Herrera, Julio, La reforma penal, Hall y Cía., Buenos Aires, 1911, 704 p.

La Rosa, Mariano, Exención de prisión y excarcelación, Astrea, Buenos Aires, 2006, 555 p.

Levaggi, Abelardo, Historia derecho penal argentino, Perrot, Buenos Aires,1978, 213 p.

Levaggi, Abelardo, "La codificación del procedimiento criminal en la Argentina en la segunda mitad del siglo XIX”. Revista de Historia del Derecho. Buenos Aires, ํo.11, 1983, p. 121-199.

Levaggi, Abelardo, “Tomás Jofré, Introductor de Giuseppe Chiovenda en el Derecho Argentino. Revista Electrónica del Instituto de Investigaciones “Ambrosio L. Gioja”, Buenos Aires, n4, 2009, p. 99-106.

Maier, Julio, Derecho procesal penal, Fundamentos, Tomo 1, 2 ed. 3 impresión, Editores del Puerto, Buenos Aires, 2004, 883 p.

Marteau, Félix, Las palabras del orden. Proyecto republicano y cuestión criminal en Argentina. Buenos Aires 1880-1930, Ediciones del Puerto, Buenos Aires, 2003, 216 p.

Moroni Marisa \& Casullo Fernando \& Carrizo Gabriel (eds.), Justicia, seguridad y castigo Concepciones y prácticas cotidianas en Patagonia (1884-1955), Prohistoria, Buenos Aires, 2018, 260 p.

Núñez, Jorge, “Algunos comentarios acerca del desarrollo y límites del positivismo criminológico en la Argentina (1903-1927)", Horizontes y convergencias, 2009. www.Horizontesyc.com.ar/ horizontes_20/index.php/investigaciones/. Consultado, 2 de marzo 2013.

Palacio, Juan (Dir.) Historia de la provincia de Buenos Aires: de la federalización de Buenos Aires al advenimiento del Peronismo (1880-1943), V. 4, Edhasa/Unipe, Buenos Aires, 2013, 468 p.

Palomeque, Alberto, Comentarios y crítica al nuevo código de procedimientos penal de la provincia de Buenos Aires, Sopena, Buenos Aires, 1916, 158 p.

Pastor, Daniel, El plazo Razonable en el proceso del estado de derecho, Ad-Hoc, Buenos Aires, 2002, 704 p.

Salvatore, Ricardo \& Carlos Aguirre, (eds). The Birth of the Penitentiary in Latin America. Essays on Criminology, Prison Reform, and Social Control 1830-1940, University of Texas Press, Austin, 1996, 279 p.

Salvatore, Ricardo, “Criminología positivista, reforma de prisiones y la cuestión social/obrera en Argentina”, en Suriano, Juan (Comp.) La cuestión social en Argentina1870-1943, La Colmena, Buenos Aires, 2004, p 127-158. 
Salvatore, Ricardo, Subalternos, derechos y justicia penal. Ensayos de historia social y cultural Argentina 1829-1940, Gedisa, Barcelona, 2010, 351.p.

Salvatore, Ricardo, "Judging violent crimes: patterns of sentencing in modern Argentina, 18781948" en Johnson, Eric \& Salvatore, Ricardo \& Spierenburg, Petrus (Ed.) Murder and violence in modern Latin América, Wiley-Blackwell, Nova Jersey, 2013, p. 82-103.

Salvatore Ricardo \& Aguirre Carlos, "Revisitando El nacimiento de la penitenciaría en América Latina veinte años después”, Revista de Historia de las Prisiones, Buenos Aires, no4, 2017, p. 7-42.

Sedeillan, Gisela, La justicia penal en Buenos Aires. Instituciones, prácticas y codificación del derecho (1877-1906), Biblos, Buenos Aires, 2012, 219 p.

Sedeillan, Gisela, "Las razones de la amplia procedencia de la prisión preventiva a fines del siglo XIX. Una mirada a través del análisis de la administración judicial en la provincia de Buenos Aires (1877-1906)" Revista de historia del derecho, Buenos Aires, nº43, 2012, p. 141-163.

Sedeillan, Gisela, "Procedimiento judicial y prisión preventiva: proyectos de reforma en la provincia de Buenos Aires ante la sobrepoblación carcelaria (1903-1915)”, en Salvatore, Ricardo \& Barreneche, Osvaldo (Ed.), El delito y el orden en perspectiva histórica. Prohistoria, Rosario, 2013, p. 61-78.

Sedeillan, Gisela, "El desafío de revertir la congestión de los tribunales bonaerenses a comienzos del siglo XX: la mirada en el desempeño judicial", Revista de Historia del Derecho, Buenos Aires, n50, 2015, p. 227-253.

Sedeillan, Gisela, "El servicio público de defensa penal en la provincia de Buenos Aires: caminos propuestos para su fortalecimiento a principios del siglo XX", Trashumante. Revista Americana de Historia Social, Colombia, nº9, 2017, pp. 98-121.

Sedeillan, Gisela, "La administración de justicia ante demandas de mayor eficacia para penalizar los delitos contra la propiedad: (Provincia de Buenos Aires - 1915-1921)", Passagens, Río de Janeiro, vol. 11, n², 2019, p. 203-222.

Sedeillan, Gisela, "Soluciones prácticas para agilizar el servicio de justicia en segunda instancia en la provincia de Buenos Aires (La ley no3560 de 1914)”, Revista Historia de Derecho, Buenos Aires, no59, 2020, p. 79-105.

Sozzo, Máximo, "Florencio Varela y el nacimiento del liberalismo penal en la Argentina", Nueva Doctrina Penal, Buenos Aires, Del Puerto, 2007, p. 635-648.

Sozzo, Máximo, "Populismo punitivo, proyecto normalizador y 'prisión depósito' en Argentina", Nueva Doctrina Penal, Buenos Aires, Del Puerto, 2007, p. 527-578.

Sozzo, Máximo, "Los exóticos del crimen: inmigración, delito y criminología positivista en la Argentina (1887-1914)”, Delito y Sociedad, Rosario, vol. 20, n³2, 2011, p. 19-51.

Sozzo, Máximo, “A manera de epílogo. Cuestiones de responsabilidad entre dispositivo penal y dispositivo psiquiátrico. Materiales para el debate desde Argentina", Delito y Sociedad, Rosario, vol. $1, n^{\circ} 13,2016$, p. 163-182.

Tau Anzoátegui, Víctor, “Los juristas argentinos de la generación de 1910" Revista de Historia del Derecho, Buenos Aires, n²,1974, p. 225-283.

Tau Anzoátegui, Víctor, "La jurisprudencia civil en la cultura jurídica Argentina. (S.XIX-XX)", Quaderni fiorentini per la storia del pensiero giuridico moderno, vol. 40, $\mathrm{n}^{\circ} 1$, 2011, pp. 53-110.

Yangilevich, Melina, Estado y criminalidad en la frontera sur de Buenos Aires (1850-1880), Prohistoria, Rosario, 2012, $232 \mathrm{p}$. 
Yangilevich, Melina, "Vínculos complejos: cárceles, estado y sociedad en la provincia de Buenos Aires (Argentina) durante la segunda mitad del siglo XIX”, Claves. Revista de Historia, Uruguay, vol. 3, nº4, 2017, p. 165-190.

Zaffaroni, Eugenio \& Alagia, Alejandro \& Slokar, Alejandro Derecho Penal. Parte General, Ediar, Buenos Aires, 2002, 1067 p.

Zaffaroni, Eugenio, El enemigo en el derecho penal, Ediar, Buenos Aires, 2006, 226 p.

Zaffaroni, Eugenio, La cuestión criminal, Planeta, Buenos. Aires, 2012, 400 p.

Zimmermann, Eduardo, Los liberales reformistas. La cuestión social en la Argentina, Sudamericana, Universidad San Andrés, Buenos Aires, 1995, 250 p.

Zimmermann, “Un espíritu nuevo"; la cuestión social y el derecho en la Argentina (1890-1930). Revista de Indias, España, vol.73, n²57, 2013, p. 81-106.

\section{NOTAS}

1. Suprema Corte de Buenos Aires, Sección Histórica. Departamento Judicial Dolores. Fondo Penal (DJD. FP) Paquete (P.) 300, orden (O.) 2, (información extraída de la tapa del expediente).

2. El artículo 49 establecía: el tiempo de prisión preventiva que hubiere sufrido el condenado, se computará: por tres días de prisión uno de presidio; por dos días de prisión, uno de penitenciaria; por uno de prisión otro de la misma pena; por dos días de arresto uno de prisión, y por uno de esta pena, cuatro pesos de multa. Beneficio restringido por ley posterior; véase: Frías, José. Código penal y código de procedimientos en lo criminal ante la justicia federal. Ordinaria y territorios nacionales, Coni. Hnos., Buenos Aires, 1904, p. 35.

El Código Penal Nacional se erigió sobre la base del proyecto del jurista Carlos Tejedor y se fundó en los preceptos centrales de la penología clásica. Proyecto que había sido adoptado por la provincia de Buenos Aires como Código propio en 1877, vigente hasta que se sancionó el corpus penal para toda la Nación. Su letra tampoco descontaba los días de encarcelamiento preventivo por entero de la pena, ni aun en los casos de ser la pena de prisión. Al respecto de la forma en que lo hacía, véase Ley 1140, artículo 171, en: https://normas.gba.gob.ar/documentos/BoQgkFlo.pdf

3. La Rosa, Mariano, Exención de prisión y excarcelación, Astrea, Buenos Aires, 2006, p. 34.

4. Existieron vaivenes con respecto a la penalidad máxima que permitía la soltura del imputado desde el Código Procesal Penal de 1888: La Rosa, M. Exensión de prisión, p.8.

5. Recién en la década de 1990 la legislación cubrió esta carencia normativa: Edwars, Enrique, Plazos de la prisión preventiva. Ley 24.390, Astrea, Buenos Aires, 1995; véase también: Pastor, Daniel, El plazo razonable en el proceso del estado de derecho, AD-HOC, Buenos Aires, 2002.

6. Véase: Salvatore, Ricardo, Subalternos, derechos y justicia penal. Ensayos de historia social y cultural argentina 1829-1940, Gedisa, Barcelona, 2010, p. 260-266.

7. Caimari, Lila. Apenas un delincuente. Crimen, castigo y cultura en la Argentina, 1880-1955, Siglo XXI, Buenos Aires, 2004, p.111.

8. Caimari, L., Apenas un delincuente, Op. Cit., p.111-112.

9. Ferrajoli, Luigi, Derecho y Razón, Teoría del garantismo penal, Trotta, Madrid, 2004, p.553.

10. La bibliografía crítica sobre este instituto es muy amplia, especialmente desde 1983. Puede consultarse al respecto: Bovino, Alberto, Problema de derecho procesal penal contemporáneo, Editores del Puerto, 1998; Binder, Alberto, Introducción al derecho procesal penal, Ad-hoc, Buenos Aires, 1999; Zaffaroni, Eugenio \& Alagia, Alejandro \& Slokar, Alejandro, Derecho Penal. Parte General, Ediar, Buenos Aires, 2002; Zaffaroni, E., El enemigo en el derecho penal, Ediar, Buenos Aires, 2006; Zaffaroni, E., La cuestión criminal, Planeta, Buenos. Aires, 2012; Caferata Nores, José, Proceso Penal y 
Derechos humanos, Del Puerto, Buenos. Aires, 2011, p.211-234; Sozzo, Máximo, "Populismo punitivo, proyecto normalizador y "prisión depósito" en Argentina", Nueva Doctrina Penal, n. ${ }^{\circ}$, Buenos Aires, 2007, p. 527-578, Cesano, José, “Tendencias de la política criminal argentina en el marco de la política criminal latinoamericana. Críticas y sugerencias a partir de un análisis comparativo", Boletín Mexicano de Derecho Comparado, México, no126, 2009, p. 1281-1303, entre muchos otros trabajos.

11. Sobre la justicia entendida como campo: Bourdieu, Pierre. La fuerza del Derecho: elementos para una sociología del campo jurídico, Uniandes, Bogotá, 2000. Desde esta perspectiva se ha destacado la importancia de atender las tensiones y el conflicto en su interior para entender las transformaciones penales: Goodman, Philip \& Page, Joshua \& Phelps, Michelle, Breaking the pendulum. The long struggle over criminal justice, Oxford University Press, 2017.

12. Sedeillan, Gisela, "Las razones de la amplia procedencia de la prisión preventiva a fines del siglo XIX. Una mirada a través del análisis de la administración judicial en la provincia de Buenos Aires (1877-1906)" Revista de Historia del Derecho, Buenos Aires, n.ํ4, 2012, p. 141-163.

13. Sedeillan, G., "Procedimiento judicial y prisión preventiva: proyectos de reforma en la provincia de Buenos Aires ante la sobrepoblación carcelaria (1903-1915)”, en Salvatore, Ricardo \& Barreneche, Osvaldo (Ed.), El delito y el orden en perspectiva histórica, Prohistoria, Rosario, 2013, p. 61-78.

14. Alvarado Vellosso, Adolfo, Lecciones de derecho procesal penal, Adaptadas a la legislación procesal y civil penal de la provincia de Buenos Aires, Astrea, Buenos Aires, 2015, p. 63. Este código fue promulgado el 15-1-1915, sustituyó al de 1906 y estuvo vigente hasta 1998 con modificaciones. Maier ha señalado que fracasó en su intención de modernizar las instituciones penales, aunque destacó que desde el punto de vista teórico académico, su autor y el movimiento que creó, significaron el primer peldaño crítico a la tradición inquisitiva ya que introdujeron definitivamente el germen de su reforma: Maier, Julio, Derecho procesal penal, Fundamentos, Tomo 1, Del Puerto, Buenos Aires, 2004, p. 415.

15. El trabajo se inscribe en una línea historiográfica que en las últimas décadas desde diferentes perspectivas interdisciplinarias ha mostrado que el derecho debe ser entendido como una arena de lucha ambigua, cuyos límites y parámetros son a su vez el resultado de disputas y negociaciones. Véase: Carlos Aguirre \& Ricardo Salvatore, “Escribir la historia del derecho, el delito y el castigo en América Latina", Revista Historia y Justicia, Chile, no 8, 2017, p. 226; Barreneche, Osvaldo, "Las instituciones de seguridad y del castigo en Argentina y América Latina. Recorrido historiográfico, desafíos y propuestas de diálogo con la historia del derecho" Revista de Historia de las Prisiones, Argentina, no1, 2015, p. 5-33. Acerca del funcionamiento de algunas de estas instituciones de castigo desde una escala regional, véase: Moroni, Marisa \& Casullo, Fernando \& Carrizo, Gabriel (eds). Justicia, seguridad y castigo Concepciones y prácticas cotidianas en Patagonia (1884-1955), Prohistoria, Rosario, 2018.

16. No nos detendremos en la justicia de paz, lega, con jurisdicción en delitos menores a un año de arresto sino en la letrada. Esta última estaba conformada en primera instancia por juzgados unipersonales y en segunda por Cámaras de Apelación con tres jueces de mayor experiencia. Por último, la Suprema Corte de Justicia, máximo tribunal constituido por cinco vocales y un procurador, atendía recursos extraordinarios por inaplicabilidad de la ley o inconstitucionalidad. Acerca de la configuración de la estructura judicial: Corva, María, Constituir el gobierno, afianzar la justicia. El poder judicial de la provincia de Buenos Aires (1853-1881), Prohistoria, Rosario, 2014.

17. Al respecto, véase: Calandria, Sol, "En busca de un nuevo orden provincial. El poder judicial y el fuero penal en la provincia de Buenos Aires (1881-1915)" Revista de Historia del Derecho, Buenos Aires, n51, 2016, p. 29.

18. Fueron consultados los Libros que se encuentran publicados en: http://www.scba.gov.ar/ AcuerdosySentencias/Consulta.asp. 
19. El aumento de la criminalidad formó parte junto a otras problemáticas de la "cuestión social", al respecto: Zimmermann, Eduardo, Los liberales reformistas. La cuestión social en la Argentina 1890-1916, Sudamericana, Buenos Aires, 1995.

20. Sobre los discursos penales modernos anteriores al impacto del positivismo: Barreneche, Osvaldo: Dentro de la ley TODO. La justicia criminal de Buenos Aires en la etapa formativa del sistema penal moderno de la Argentina, Al Margen, La Plata, 2001; Marteau, Félix, Las palabras del orden. Proyecto republicano y cuestión criminal en Argentina. Buenos Aires 1880-1930, Del Puerto, Buenos Aires, 2003, Caimari, L. Apenas un delincuente, Op. Cit., Sozzo, Máximo, "Florencio Varela y el nacimiento del liberalismo penal en la Argentina", Nueva Doctrina Penal, Del Puerto, Buenos Aires, 2007, p. 635-648. Los estudios sobre la criminología positivista en Argentina son variados, de modo que solo mencionaremos algunos de ellos por una cuestión de espacio: Zimmermann Eduardo Los liberales reformistas, Op. Cit; Salvatore, Ricardo, "Criminología positivista, reforma de prisiones y la cuestión social/obrera en Argentina” en Suriano, Juan, La cuestión social en Argentina, La Colmena, Buenos Aires, 2004; Salvatore, R, Subalternos, derechos, Op. Cit; Marteau, F. Las palabras, Op. Cit; Caimari, L. Apenas un delincuente, Op. Cit.; Creazzo, Giuditta, El positivismo criminológico italiano en la Argentina, Ediar, Buenos Aires, 2007; Núñez, Jorge, "Algunos comentarios acerca del desarrollo y límites del positivismo criminológico en la Argentina (1903-1927)", Horizontes y convergencias, 2009; Sozzo, Máximo, "Los exóticos del crimen: inmigración, delito y criminología positivista en la Argentina (1887-1914)”, Delito y Sociedad, Rosario, vol. 20, n³2, 2011, p. 19-51; Dovio, Mariana \& Cesano, José, La criminalidad femenina en el discurso del positivismo criminológico argentino, Brujas, Córdoba, 2009; Cesano, José, Élites, redes intelectuales y recepción en la cultura jurídico penal de Córdoba: 1900-1950, Del Copista, Córdoba, 2011; Sozzo, M., “A manera de epílogo. Cuestiones de responsabilidad entre dispositivo penal y dispositivo psiquiátrico. Materiales para el debate desde Argentina”, Delito y Sociedad, Rosario, vol.1, n¹3, 2016, p. 163-182.

21. Jofré formó parte de esa generación de juristas que compartían inquietudes comunes como la preocupación por renovar el derecho a partir de su estudio como fenómeno científico y social: Tau Anzoátegui, Víctor: "Los juristas argentinos de la generación de 1910" Revista de Historia del Derecho, Buenos Aires, n²,1974, p. 225-283; Víctor Tau Anzoátegui, "La jurisprudencia civil en la cultura jurídica Argentina. (S.XIX-XX)", Quaderni fiorentini per la storia del pensiero giuridico moderno, vol. 40, $\mathrm{n}^{\circ} 1,2011$, p. 53-110 Acerca de su importancia como procesalista: Levaggi, Abelardo, "Tomás Jofré, Introductor de Giuseppe Chiovenda en el Derecho Argentino", Revista Gioja, Buenos Aires, n4, 2009, p. 99-106.

22. Acerca de esta corriente: Zimmermann, E., Los liberales reformistas, Op. Cit. Sobre el nuevo espíritu de renovación, que aspiraba a transformar los procesos de formación de abogados: Zimmermann, E., "Un espíritu nuevo"; la cuestión social y el derecho en la Argentina (1890-1930)”, España, Revista de Indias, vol.73, n²57, 2013, p. 81-106.

23. La mayoría compartía una banca por el Partido Conservador. Para un panorama general respecto de la política: Palacio, Juan (Dir.). Historia de la provincia de Buenos Aires: de la federalización de Buenos Aires al advenimiento del Peronismo (1880-1943), Tomo IV, Edhasa/Unipe, Buenos Aires, 2013.

24. Véase: Salvatore, R., Subalternos, derechos, Op. Cit., p. 244-271.

25. Caimari, L., Apenas un delincuente, Op. Cit.

26. Primer Censo Penitenciario Carcelario de la República Argentina, Talleres Gráficos de la penitenciaria Nacional, Buenos Aires, 1909, p. 57-58.

27. Sobre las razones de la conformación de estos juzgados: Yangilevich, Melina, Estado y criminalidad en la frontera sur de Buenos Aires (1850-1880), Prohistoria, Rosario, 2012; Corva, M., Constituir el gobierno, Op. Cit. 
28. Existen distintas corrientes de legitimación discursiva de las medidas de coerción personal: las teorías sustancialistas y las procesalistas, véase: Zaffaroni, E. \& Alagia, A. \& Slokar, A., Derecho Penal, Op. Cit., p.169.

29. Ello se reflejaba ya antes de la codificación procesal penal, véase: Caimari L., Apenas un delincuente, Op. Cit. p. 111; Yangilevich, M., Estado y Criminalidad, Op. Cit.

30. Aspectos tratados en particular para los delitos de homicidios y atentados a la propiedad en: Sedeillan, G., La justicia penal en Buenos Aires. Instituciones, prácticas y codificación del derecho (1877-1906), Biblos, Buenos Aires, 2012; Sedeillan, Gisela, "La administración de justicia ante demandas de mayor eficacia para penalizar los delitos contra la propiedad: (Provincia de Buenos Aires: 1915-1921)”, Passagens, Rio de Janeiro, vol. 11, n², 2019, p. 203-222. En los delitos de infanticidio se ha mostrado que también era alta la proporción de no condenadas: Calandria, Sol, "Resquicios jurídicos en el discurso del poder: honra y moralidad sexual en los fallos de infanticidio (provincia de Buenos Aires)", Revista Historia y Justicia, Chile, n¹1, 2018, p. 14-41. También los sobreseimientos eran significativos en otras provincias: Casullo, Fernando, "El estado mira al sur. Administración de justicia en los Territorios Nacionales de Rio Negro y Neuquén. (1884-1920)", en Bohoslavsky, Ernesto \& Soprano, Germán (comp.) Un Estado con rostro humano. Funcionarios e instituciones estatales en Argentina (de 1880 a la actualidad), Universidad de Sarmiento/ Prometeo, Buenos Aires, 2010, p. 333- 354.

31. Sedeillan, G., "Procedimiento judicial”, Op. Cit.

32. Al respecto: Pastor, D., El plazo Razonable, Op. Cit.

33. Pastor, D. El plazo razonable, Op. Cit., p. 102.

34. El Art. 5 de la ley 2979 de 1906 establecía que toda causa debía terminarse a los dos años, no computándose las demoras a que se refiere el artículo 441. Sobre el proceso codificador en la provincia: Levaggi, Abelardo, "La codificación del procedimiento criminal en la Argentina en la segunda mitad del siglo XIX", Revista de Historia del Derecho, Buenos Aires, n¹1, 1983, p. 121-199.

35. Sobre este aspecto en particular: Sedeillan, G. "El desafío de revertir", Op. Cit.

36. Con respecto a esta problemática: Sedeillan, G. "Soluciones prácticas para agilizar el servicio de justicia en segunda instancia en la provincia de Buenos Aires (La ley no3560 de 1914)”, Revista de Historia del Derecho, Buenos Aires, n59, 2020, p.79-105.

37. Biblioteca Municipal Leopoldo Marechal, (BMLM), Mar del Plata, Argentina, Fondo Tesoro: Diario de Sesiones de la Cámara de Diputados, sesión 11-08-1909, Talleres de Impresiones Oficiales, La Plata, 1910, p. 289-301. Más detalles en Sedeillan G., "Procedimiento judicial”, Op. Cit. 38. (BMLM) Diario de Sesiones de la Cámara de Diputados de la provincia de Buenos Aires, sesión 28-07-1911, Taller de Impresiones Oficiales, La Plata, 1912, p. 359.

39. Sobre este proyecto: Jofré, Tomás, Proyecto de código de procedimiento penal, Talleres Gráficos Suarez, Buenos Aires, 1914, p.110. El mismo también redujo el plazo máximo para que el proceso finalice.

40. El Código de 1887 establecía que los condenados a presidio serían empleados en trabajos duros y penosos, la reforma 4189, modificó la noción de la pena de presidio diciendo que se cumpliría "con trabajos forzados en establecimientos destinados al efecto". Desde entonces, la pena de presidio pasó a ser de trabajos forzados en establecimientos especiales; la de penitenciaría, de los mismos trabajos en otros establecimientos; y la de prisión, de trabajos acordes con los reglamentos carcelarios: Levaggi, Abelardo, Historia derecho penal argentino, Perrot, Buenos Aires, 1978, p.156. Sobre las distinciones al respecto en los diferentes proyectos: Zaffaroni, E. \& Alagia, A. \& Slokar, A. "Derecho Penal. Op. Cit., p. 939-940.

41. Véase al respecto: Caimari, L., Apenas un delincuente, Op. Cit. En referencia a las similitudes con lo que sucedía en otros establecimientos de Latinoamérica: Salvatore, Ricardo \& Carlos Aguirre, (eds.) The Birth of the Penitentiary in Latin America. Essays on Criminology, Prison Reform, and Social Control 1830-1940, University of Texas Press, Austin, 1996; Salvatore Ricardo \& Aguirre Carlos, "Revisitando el nacimiento de la penitenciaría en América Latina veinte años después", Revista de 
Historia de las Prisiones, Buenos Aires, ํㅜ4, 2017, p. 7-42. Con respecto a las cárceles departamentales de la provincia de Buenos Aires, a fines del siglo XIX: Yangilevich, Melina, "Vínculos complejos: cárceles, estado y sociedad en la provincia de Buenos Aires (Argentina) durante la segunda mitad del siglo XIX", Claves, Montevideo, vol. 3, n4, p. 165-190.

42. Caimari, L. Apenas un delincuente, Op. Cit, p.109-135. En este sentido, la autora comenta que las pésimas condiciones de la Casa Correccional de Mujeres de Buenos Aires, sumadas a la inexistencia de cárceles femeninas en la mayoría de las provincias hacía que muchos jueces optaran por no encarcelar a las condenadas, y resolvieran enviarlas a instituciones "respetables" de otro tipo: Caimari, Lila, "Entre la celda y el hogar. Dilemas estatales del castigo femenino, 1890-1940”, Nueva Doctrina Penal, Buenos Aires, ํㅡ2, 2007, p.427-450. En esta misma línea, sostiene Freidenraij, que la realidad de las cárceles fue atendida por los jueces al decidirse absolver a niños y jóvenes infractores: Freidenraij, Claudia "Penetrar en el alma del niño": reflexiones sobre el discernimiento de los menores delincuentes (Buenos Aires, 1887-1919), Revista Gioja, Buenos Aires, nº17, 2016; p. 35-56.

43. Por ejemplo, en 1911 sobre la cárcel de San Nicolás: Libro de Acuerdos y Sentencias de la Suprema Corte de Justicia de la Provincia de Buenos Aires (LASSCPBA), Tomo IV, Serie VII, 1913, Expediente 3779 p, 269.

44. LASSCPBA, Tomo VII, Serie VII, 1913, Acuerdo, p. 491-492.

45. (BMLM) Diario de Sesiones de la Cámara de Diputados de la provincia de Buenos Aires, sesión 1-10-1913, Taller de Impresiones Oficiales, La Plata, 1914, p. 680.

46. Caimari, L. Apenas un delincuente, Op. Cit. p. 112.

47. Herrera, Julio, La reforma penal, Hall y Cía., Buenos Aires, 1911, p. 245.

48. DJD. FP, P. 142, O. 7.

49. DJD. FP, P. 235, O. 21.

50. DJD. FP, P. 278, O. 1. Véase al respecto de este recurso: LASSCPBA, Tomo III, Serie VI, 1911, Causa 146, p. 202-209.

51. Salvatore, deteniéndose en la justicia federal, destaca que el aumento que se experimentó en las penas se debió también a una mayor severidad de los jueces en respuesta a las demandas sociales. Véase: Salvatore, R., "Judging violent crimes: patterns of sentencing in modern Argentina, 1878-1948, en: Johnson, Eric \& Salvatore, Ricardo, \& Spierenburg, Peter (Ed.) Murder and violence in modern Latin América, Wiley-Blackwell, Nova Jersey, 2013, p. 82-103.

52. DJD. FP, P. 261, O. 12.

53. DJD. FP, P. 261, O. 1.

54. DJD. FP, P.259, O. 11.

55. DJD. FP, P. 267, O. 27.

56. Como han señalado distintos estudios, quienes transitaban la justicia como acusados tenían cierto grado de conocimiento sobre el funcionamiento de las instituciones y desplegaron estrategias a fin de verse favorecidos. Al respecto de ello para el espacio y periodo elegido: Di Gresia, Leandro, "Una aproximación al estudio de la cultura judicial de la población rural bonaerense: Tres Arroyos, segunda mitad del siglo XIX”, en Barriera, Darío (Coord.), La justicia y las formas de la autoridad. Organización política y justicias locales en territorios de frontera. El Río de la Plata, Córdoba, Cuyo y Tucumán, siglos XVIII-XIX, ISHIR-CONICET, 2010, p. 155-191. Sobre las tácticas judiciales desplegadas en otros contextos como Chile, puede consultarse: Brangier, Víctor, "Sentidos de 'lo justo e injusto'. Judicialización de conflictos interpersonales. Chile Central, 1824-1875", Revista Historia y Justicia, Chile, n¹, 2013, p. 1-33.

57. Sobre algunas de las propuestas legislativas presentadas a fin de mejorar la prestación del servicio: Sedeillan, Gisela, "El servicio público de defensa penal en la provincia de Buenos Aires: caminos propuestos para su fortalecimiento a principios del siglo XX. Trashumante. Revista Americana de Historia Social, Colombia, nำ, 2017, p. 98-121. 
58. Salvatore ha destacado tempranamente que la precariedad del servicio de defensa fue una característica saliente de la administración de justicia en el período de "modernización legal": Salvatore Ricardo Subalternos, derechos, Op. Cit.

59. Véase, por ejemplo: DJD. FP, P. 123 O. 7, 1890.

60. DJD. FP, P. 243, O. 16.

61. LASSCPBA, Tomo VI, Serie VII, 1914, C. B10148, p. 293-294.

62. Al respecto: Sedeillan Gisela, "Soluciones prácticas", Op. Cit.

63. LASSCPBA, Tomo VI, Serie VII, 1914, C. B10148, p. 294.

64. LASSCPBA, Tomo VI, Serie VII, 1914, C. B10148, p. 294.

65. LASSCPBA, Tomo II, Serie VIII, 1916, C. B 10995, p. 147- 153.

66. LASSCPBA, Tomo. II, Serie VIII, C. B 10995, p. 150.

67. LASSCPBA, Tomo II, Serie VIII, C. B 10995, p. 150.

68. LASSCPBA, Tomo II, Serie VIII, C. B 10995, p. 151.

69. LASSCPBA, Tomo II, Serie VIII, C, B 10995, p. 150-151.

70. En lo que respecta al problema de la excesiva duración del proceso, Pastor ha señalado que para el catálogo de derechos del imputado, el de ser juzgado dentro de un plazo razonable es una conquista reciente, véase: Pastor D., El Plazo razonable, Op. Cit, p.54.

71. Jofré, Tomás, El nuevo código de procedimiento penal de la provincia de Buenos Aires, comentado (T. II), Valerio Abeledo, 1915, p. 388.

72. Establecer en qué medida los intentos que existieron al interior del campo judicial por limitar la lesividad del cómputo inequitativo de la prisión preventiva promovieron o condicionaron el artículo 449, requiere un análisis que excede el marco de este trabajo. No obstante, esas contestaciones no pueden dejar de considerarse ante cualquier explicación que vea la reforma legal únicamente como producto del ámbito político. De hecho, el Código Procesal Penal fue el resultado de un largo proceso de elaboración desde 1908, en el que fueron consultados académicos y funcionarios de justicia.

73. Véase Jofré, T. El nuevo código, Op. Cit; Maier, J., Derecho procesal penal, Op. Cit.

74. Jofré, T. El nuevo código, Op. Cit. p. 193.

75. Véase: Jofré, T. El nuevo código, Op. Cit. p. 203 y 206.

76. Aguirre señala que en ese espacio no era menor la importancia de la escritura de cartas para todos los presos, incluso aquellos iletrados, quienes solicitaban a otros que les leyesen o escribiesen su correspondencia: Aguirre, Carlos, La cárcel y la ciudad letrada: hacia una historia cultural de la prisión en el Perú del siglo XX", en Palma Alvarado, Daniel (Ed.), Delincuentes, policías y justicias en América Latina, siglos XIX-XX, Universidad Alberto Hurtado, Santiago de Chile, 2015, p. 167; Salvatore R. \& Aguirre C., "Revisitando el nacimiento...Op. Cit. p.25.

77. DJD. FP, P. 261, O. 12.

78. DJD. FP, P. 125 , O. 7.

79. Véase LASSCPBA, Tomo V, Serie VIII, 1918, C. B 11708, p. 531.

80. LASSCPBA, Tomo VI, Serie VIII, 1921, C. B11696, p. 563-564.

81. LASSCPBA, Tomo VI, Serie VIII, 1921, C. B11696, p. 564.

82. Palomeque, Alberto, Comentarios y crítica al nuevo código de procedimientos penal de la provincia de Buenos Aires, Sopena, Buenos Aires, 1916, p.102.

83. Palomeque, A. Comentarios y crítica, Op. Cit., p. 99.

84. Jofré, T. El nuevo código, Op. Cit., p. 390. Palabras que Jofré reprodujo al comentar el Código Penal sancionado en 1921, cuya letra mantuvo cómputos diferenciados del tiempo de prisión preventiva según sea la pena prisión o reclusión, véase: Jofré T., El código penal, Valerio Abeledo, Buenos Aires, 1922, p. 70.

85. Bourdieu, P. La fuerza del Derecho, Op. Cit. 


\section{RESÚMENES}

Este artículo detiene la mirada en la administración de justicia penal en la provincia de Buenos Aires entre 1896 y 1915, dentro del marco del proceso de reforma del derecho procesal penal codificado. Se centra particularmente en los efectos lesivos que implicaba para el condenado el cómputo diferenciado de la prisión preventiva establecido en el Código Penal Nacional de 1887, con el propósito de identificar si en un contexto donde se puso en discusión la necesidad de fortalecer los derechos de los imputados existieron matices en la interpretación de la ley. El objetivo principal es dimensionar el impacto que tuvieron algunos cambios introducidos en el Código de Procedimientos Penal de 1915 para los condenados.

This article investigates the administration of criminal justice in the province of Buenos Aires between 1896 and 1915, within the framework of the reform process of criminal procedural law codified. It focuses on the harmful effects that the differentiated computation of preventive detention established in the 1887 penal code for the convicted person, with the purpose of identifying whether in a context of discussion about the need of strengthen the rights of the accused in the process, there were nuances in the interpretation of the law. The main objective is to assess the impact that some changes introduced in the 1915 code of procedures had on those convicts.

Cet article s'intéresse à l'administration de la justice pénale dans la province de Buenos Aires entre 1896 et 1915, dans le cadre du processus de réforme du droit codifié de la procédure pénale. Elle se concentre en particulier sur les effets néfastes pour la personne condamnée du calcul différencié de la détention provisoire établi dans le Code pénal national de 1887, dans le but d'identifier si, dans un contexte où la nécessité de renforcer les droits de l'accusé était discutée, il y avait des nuances dans l'interprétation de la loi. L'objectif principal est d'évaluer l'impact que certains des changements introduits dans le code de procédure pénale de 1915 ont eu sur les personnes condamnées.

\section{ÍNDICE}

Palabras claves: prisión preventiva, inicios de siglo XX, reforma procesal penal, provincia de Buenos Aires

Keywords: preventive prison, early 20th century, criminal procedural reform, province of Buenos Aires

Mots-clés: Détention provisoire, début 20e siècle, réforme de la procédure criminelle, province de Buenos Aires

\section{AUTOR}

\section{GISELA SEDEILLAN}

Doctora en Historia, Universidad Nacional del Centro (UNICEN), Argentina. Investigadora Adjunta del CONICET/ Instituto de Geografía, Historia y Cs. Sociales (IGEHCS/UNICEN). Profesora adjunta, Facultad de Derecho de la Universidad Nacional de Mar del Plata, Argentina.

Correo electrónico: giselatandil[at]hotmail.com.

Este trabajo fue realizado en el marco del proyecto en curso titulado "La renovación de la justicia 
criminal en la provincia de Buenos Aires ante el cuestionamiento del sistema penal: 1906 y 1930", financiado por CONICET.com 